\title{
Randomized phase I trials of the safety/ tolerability of anti-LINGO-1 monoclonal antibody BIIB033
}

\section{OPEN}

Jonathan Q. Tran, PharmD

Jitesh Rana, MD

Frederik Barkhof, MD

Isaac Melamed, MD

Hakop Gevorkyan, MD

Mike P. Wattjes, MD

Remko de Jong, MSc

Kristin Brosofsky, MPH

Soma Ray, PhD

Lei $\mathrm{Xu}, \mathrm{PhD}$

Jim Zhao, $\mathrm{PhD}$

Edward Parr, $\mathrm{PhD}$

Diego Cadavid, MD

Correspondence to

Dr. Cadavid:

diego.cadavid@biogenidec.com

\section{See editorial}

Supplemental data at Neurology.org/nn
ABSTRACT

Objective: To evaluate the safety, tolerability, and pharmacokinetics (PK) of BIIB033 (antiLINGO-1 monoclonal antibody) in healthy volunteers and participants with multiple sclerosis (MS).

Methods: In 2 separate randomized, placebo-controlled studies, single ascending doses (SAD; $0.1-100 \mathrm{mg} / \mathrm{kg}$ ) of BIIB033 or placebo were administered via IV infusion or subcutaneous injection to 72 healthy volunteers, and multiple ascending doses (MAD; 0.3-100 mg/kg; 2 doses separated by 14 days) of BIIB033 or placebo were administered via IV infusion to 47 participants with relapsing-remitting or secondary progressive MS. Safety assessments included adverse event (AE) monitoring, neurologic examinations, conventional and nonconventional MRI, EEG, optical coherence tomography, retinal examinations, and evoked potentials. Serum and CSF PK as well as the immunogenicity of BlIB033 were also evaluated.

Results: All 72 healthy volunteers and 47 participants with MS were included in the safety analyses. BIIB033 infusions were well tolerated. The frequency of AEs was similar between BIIB033 and placebo. There were no serious AEs or deaths. No clinically significant changes in any of the safety measures were observed. BIIB033 PK was similar between healthy volunteers and participants with MS. Doses of $\geq 10 \mathrm{mg} / \mathrm{kg}$ resulted in BllB033 concentrations similar to or higher than the concentration associated with $90 \%$ of the maximum remyelination effect in rat remyelination studies. The incidence of anti-drug antibody production was low.

Conclusions: The emerging safety, tolerability, and PK of BIIB033 support advancing BIIB033 into phase II clinical development as a potential treatment for CNS demyelination disorders.

Classification of evidence: This study provides Class I evidence that BIIB033 is well tolerated and safe (serious adverse event rate 0\%, 95\% confidence interval 0-7.6\%). Neurol Neuroimmunol Neuroinflammation 2014;1:e18; doi: 10.1212/NXI.0000000000000018

\section{GLOSSARY}

$\mathbf{A E}=$ adverse event $; \mathbf{A U C}=$ area under the time-concentration curve; $\mathbf{C}_{\max }=$ maximum serum concentration; $\mathbf{D T I}=$ diffusion tensor imaging; $\mathbf{G d}$ = gadolinium; $\mathbf{l} \mathbf{g}=$ immunoglobulin; $\mathbf{m A b}=$ monoclonal antibody; $\mathbf{M A D}=$ multiple ascending dose; $\mathbf{M S}=$ multiple sclerosis; $\mathbf{M T}=$ magnetization transfer; $\mathbf{M T R}=$ magnetization transfer ratio; $\mathbf{N A W M}=$ normal-appearing white matter; PK = pharmacokinetics; RRMS = relapsing-remitting MS; SAD = single ascending dose; SC = subcutaneous; SPMS = secondary progressive MS; SSEP = somatosensory evoked potential; $\mathbf{t}_{1 / 2}=$ half-life; $\mathbf{T}_{\max }=$ time to maximum serum concentration; VEP = visual evoked potential; $\mathbf{V}_{\mathbf{S S}}=$ steady-state volume of distribution.

Currently available therapies for multiple sclerosis (MS) do not facilitate remyelination or axonal repair in the CNS. These processes are hypothesized to be actively suppressed by signaling pathways that are potential targets for pharmacologic interventions. ${ }^{1}$ One such signaling pathway involves leucine-rich repeat and immunoglobulin (Ig) domain-containing neurite outgrowth inhibitor Nogo receptor-interacting protein-1 (LINGO-1), a glycoprotein selectively expressed in neurons and oligodendrocyte progenitor cells in the CNS. ${ }^{2-4}$ LINGO-1 negatively regulates myelination through distinct mechanisms involving activation of RhoA-GTPase ${ }^{5}$ as well as

From Biogen Idec (J.Q.T., J.R., S.R., L.X., D.C.), Cambridge, MA; VU Medical Center (F.B., M.P.W., R.D.), Amsterdam, the Netherlands; IMMUNOe (I.M.), Centennial, CO; PAREXEL International (H.G.), Glendale, CA; ALG Partners (K.B.), Natick, MA; and Excel Scientific Solutions (E.P.), Southport, CT. J.Z. is a former employee of Biogen Idec.

Go to Neurology.org/nn for full disclosures. Funding information and disclosures deemed relevant by the authors, if any, are provided at the end of the article. The Article Processing Charge was paid by Biogen Idec Inc.

This is an open access article distributed under the terms of the Creative Commons Attribution-Noncommercial No Derivative 3.0 License, which permits downloading and sharing the work provided it is properly cited. The work cannot be changed in any way or used commercially. 
nerve growth factor and the tyrosine kinase $\mathrm{A}$ receptor. ${ }^{6}$ Blockade of LINGO-1 has been shown to result in remyelination in various animal models of CNS demyelination. ${ }^{4,7}$

BIIB033 is a human aglycosyl IgG1 monoclonal antibody (mAb) that binds LINGO-1 with high affinity and specificity and is being developed as an investigational product to lead to remyelination and axonal protection and/or repair in patients with MS. ${ }^{4}$ Although CNS penetration of anti-LINGO-1 mAbs is limited, ${ }^{8}$ the CNSspecific expression of LINGO-1 created an opportunity to deliver efficacious concentrations of BIIB033 by giving high doses systemically. We conducted the first-in-human studies to evaluate the safety and tolerability of BIIB033 in healthy volunteers and participants with relapsingremitting MS (RRMS) or secondary progressive MS (SPMS). Serum and CSF pharmacokinetics (PK) as well as immunogenicity of BIIB033 were also evaluated in both studies. Finally, conventional and nonconventional MRI (magnetization transfer $[\mathrm{MT}]$ and diffusion tensor imaging $[\mathrm{DTI}]^{9}$ ) was used to evaluate the safety of BIIB033 in both studies and as a pilot exploratory efficacy endpoint for preexisting brain lesions in the multiple ascending dose (MAD) study.

METHODS Study designs. Two randomized, blind, placebo-controlled phase I studies were conducted: the single ascending dose (SAD) study in healthy volunteers (ClinicalTrials.gov identifier NCT01052506) and the MAD study in participants with RRMS or SPMS (ClinicalTrials.gov identifier NCT01244139). In the SAD study, eligible healthy adult participants were randomized 3:1 to receive single doses of BIIB033 (IV: 0.1, 0.3, 1.0, 3.0, 10, 30, 60, or $100 \mathrm{mg} / \mathrm{kg}$; subcutaneous [SC]: $3.0 \mathrm{mg} / \mathrm{kg} ; \mathrm{n}=6$ each, total $\mathrm{N}=54$ ) or IV placebo $(0.9 \%$ saline; total $\mathrm{N}=18)$. In the MAD study, eligible adult participants with MS were randomized 2:1 to receive IV BIIB033 $(\mathrm{n}=4$ each at $0.3,1.0,3.0,10,30,60$, and $100 \mathrm{mg} / \mathrm{kg}$; total $\mathrm{N}=28$ ) or placebo (total $\mathrm{N}=14$ ); the 2 doses were given 12-14 days apart. A single-dose group $(\mathrm{n}=5$; 4 BIIB033 and 1 placebo) was added to assess the tolerability of $100 \mathrm{mg} / \mathrm{kg}$ at a faster infusion rate ( 80 minutes instead of 2.75 hours). Both studies were conducted in a staggered fashion in which available safety and PK data from the SAD study were evaluated prior to dose escalation in the MAD study.

In both studies, participants and study site personnel were blinded to treatment assignment. An unblinded study pharmacist prepared study treatments and randomized participants according to a randomization code developed by Biogen Idec but was not involved in assessments.

Participants. The SAD study was conducted at one site in the Netherlands and one site in the United States. Eligible participants (aged 25-55 years) were healthy and had a body mass index of $18-30 \mathrm{~kg} / \mathrm{m}^{2}$. Male participants were required to practice contraception for $\geq 6$ months from the first study medication dose; females of childbearing potential were not eligible. Key exclusion criteria included history of any clinically significant systemic disease; abnormal laboratory tests or ECGs; history or positive test for HIV, hepatitis C, or hepatitis B virus; treatment with any prescription medication ( $<28$ days before screening) or over-thecounter products (14 days before screening); history of alcohol or substance abuse; and regular use of any tobacco product within 3 months of screening.

The MAD study was conducted at one site in the United States. Eligible participants (aged 18-60 years; body mass index of $18-30 \mathrm{~kg} / \mathrm{m}^{2}$ ) were diagnosed with RRMS or SPMS (revised $2005 \mathrm{McDonald}_{\text {criteria }}{ }^{10}$ ) and had an Expanded Disability Status Scale ${ }^{11}$ score between 1.0 and 6.0 at screening. Male and female participants of childbearing potential were required to practice contraception during the study and for $\geq 6$ months after the last study medication dose. In addition to the key exclusion criteria listed above for the SAD study, participants were ineligible if they had any of the following: a relapse that had not resolved within 30 days of screening; allergy or intolerance for gadolinium (Gd) contrast agents; prior treatment with total lymphoid irradiation, $\mathrm{T}$ cell or T-cell receptor vaccination, alemtuzumab, mitoxantrone, cyclophosphamide, cladribine, rituximab, or fingolimod; treatment within 12 months with one of the following: natalizumab, daclizumab, azathioprine, methotrexate, IV Ig, plasmapheresis, or mycophenolate mofetil; or treatment within 1 month with high-dose oral or IV steroids.

Standard protocol approvals, registrations, and patient consents. The SAD and MAD study protocols were reviewed and approved by the local institutional review boards. The studies were conducted in accordance with the International Conference on Harmonization Guidelines for Good Clinical Practice, the European Union Clinical Trial Directive 2001/20/EC, and the principles outlined in the Declaration of Helsinki. Written informed consent was obtained from all participants.

Safety and tolerability assessments. In both studies, evaluation of the safety and tolerability of BIIB033 was the primary objective (Class I evidence). Clinical safety measures included physical and neurologic examinations, vital signs, ECGs, and treatmentemergent adverse events (AEs). Laboratory measures included hematology, blood chemistry, and urinalysis. In the SAD study, brain MRI scans with MT ratio (MTR) were performed at weeks 4 and 8 . The MTR was used to measure the integrity of the cerebral white matter in 6 regions of normal-appearing white matter (NAWM). To test for any potential neurologic effects in the SAD study, visual evoked potentials (VEPs), somatosensory evoked potentials (SSEPs; performed in one leg and one arm), EEGs, and retinal examination with optical coherence tomography and photography were also assessed (see appendix e-1 at Neurology.org/nn). In the MAD study, conventional brain MRI (T1-weighted with and without Gd enhancement, T2-weighted), and quantitative MRI sequences (MTR and DTI) were performed at weeks 8 and 16. The MTR and DTI of preexisting lesions and nonlesional NAWM were used as exploratory endpoints to assess short-term treatment safety and efficacy. Changes in brain volume were also analyzed. Detailed information on MRI methods is provided in appendix e-1.

For VEPs and SSEPs, abnormalities signifying pathology are typically regarded as values falling $2.5-3 \mathrm{SD}$ above values for agematched control samples from the normal population. However, for the purposes of the current study, this was considered insufficiently sensitive to detect presymptomatic changes. Therefore, a more appropriate basis was used based on protocols applied to intraoperative monitoring in which an increase of $\geq 10 \%$ in the latency of the evoked potential or a decrease of $\geq 50 \%$ in its 
A

72 Participants randomized
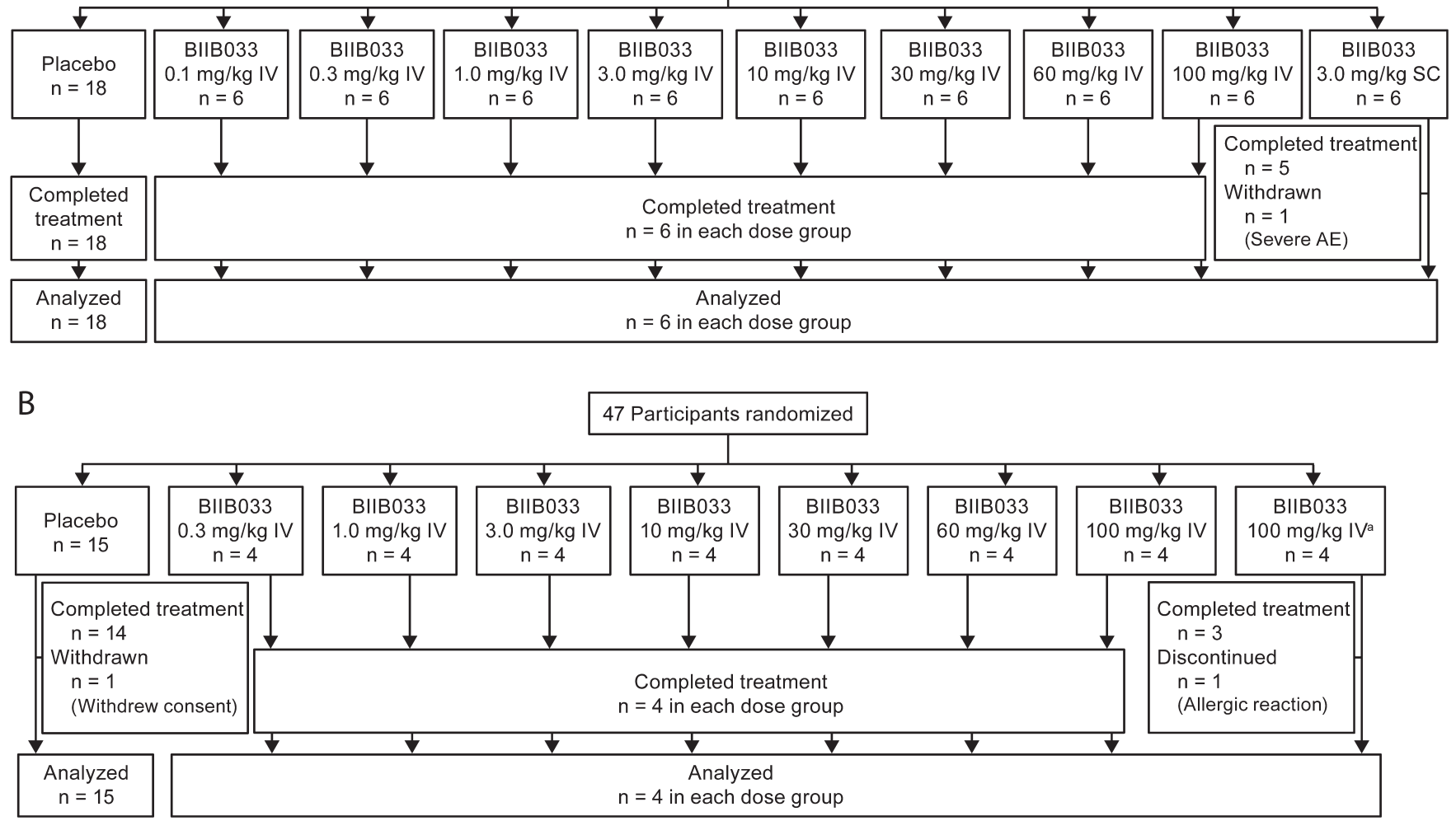

(A) Single ascending dose study and (B) multiple ascending dose study. Abbreviations: $\mathrm{AE}=$ adverse event; $\mathrm{SC}=$ subcutaneous. ${ }^{\mathrm{B}} 80$-minute infusion time.

amplitude was considered "abnormal." Determinations of abnormalities for results of EEG, brain MRI, and retinal examinations were each made by expert interpretation of specialists (EEG: neurologist/electrophyisologist; brain MRI: neuroradiologist; retinal examination: neuro-ophthalmologist)

Immunogenicity. In both studies, immunogenicity (a secondary endpoint) was tested by analyzing serum anti-BIIB033 antibody levels using biotin- and digoxigenin-labeled BIIB033 in an ELISA of blood samples collected at baseline (predose), at various times during the treatment period, and at the end of treatment or discontinuation (Assay Services Laboratory [Biogen Idec], Cambridge, MA). In predose testing, this assay had a 5\% false-positive rate.

PK assessments. Evaluation of serum and CSF PK was a secondary objective in both studies. Serial PK blood samples for the measurement of serum BIIB033 concentration were collected for up to 16 weeks after dosing. Serum concentrations were determined with an ELISA using anti-BIIB033 2H09 (performed by Assay Services Laboratory). Serum PK values were estimated using noncompartmental analysis (Phoenix WinNonlin 6.2.1, Pharsight, St. Louis, MO) and included maximum serum concentration $\left(\mathrm{C}_{\max }\right)$, time to maximum serum concentration $\left(\mathrm{T}_{\max }\right)$, area under the time-concentration curve from time extrapolated to infinity (AUC $\left.{ }_{\text {inf }}\right)$ for the SAD study or AUC over a dosing interva $\left(\mathrm{AUC}_{\mathrm{tau}}\right)$ for the MAD study, terminal elimination half-life ( $\left.\mathrm{t}_{1 / 2}\right)$, clearance, and steady-state volume of distribution $\left(\mathrm{V}_{\mathrm{ss}}\right)$.

The CSF samples for the measurement of BIIB033 concentration were collected by lumbar puncture at baseline and 2 weeks postdose in the SAD study in healthy volunteers (for doses between $10 \mathrm{mg} / \mathrm{kg}$ and $100 \mathrm{mg} / \mathrm{kg} \mathrm{IV} \mathrm{and} 3 \mathrm{mg} / \mathrm{kg} \mathrm{SC)}$ or 2 weeks after the second $/$ last dose in the MAD study in participants with MS (for all dose levels). Concentrations of BIIB033 in CSF were determined using immunoPCR (Imperacer, Chimera Biotec, Dortmund, Germany).

Statistical analyses. All safety analyses were performed on the safety population, defined as all participants who were randomized and dosed with study medication. All AEs, serious AEs, clinical laboratory abnormalities, vital signs, physical and neurologic examinations, ECG and continuous cardiac monitoring, VEPs, SSEPs, EEG, retinal examinations, and brain MRI in each group were evaluated and compared with those given placebo. Data from participants on placebo were counted as a single group in each study. All PK analyses were performed on the PK population, which included all randomized participants who received study medication and had measurable BIIB033 concentrations.

RESULTS Demographics and participant disposition. Of the 72 healthy volunteers enrolled, randomized, and dosed in the SAD study between January 2010 and October 2011, 71 completed the study (figure 1). One participant in the $3.0-\mathrm{mg} / \mathrm{kg}$ SC group was withdrawn owing to severe AEs (affective disorder and toxicity) after consuming amphetamines and alcohol (protocol violation). Of the 47 participants with MS who were dosed in the MAD study between October 2010 and April 2012, 46 completed the study. One 


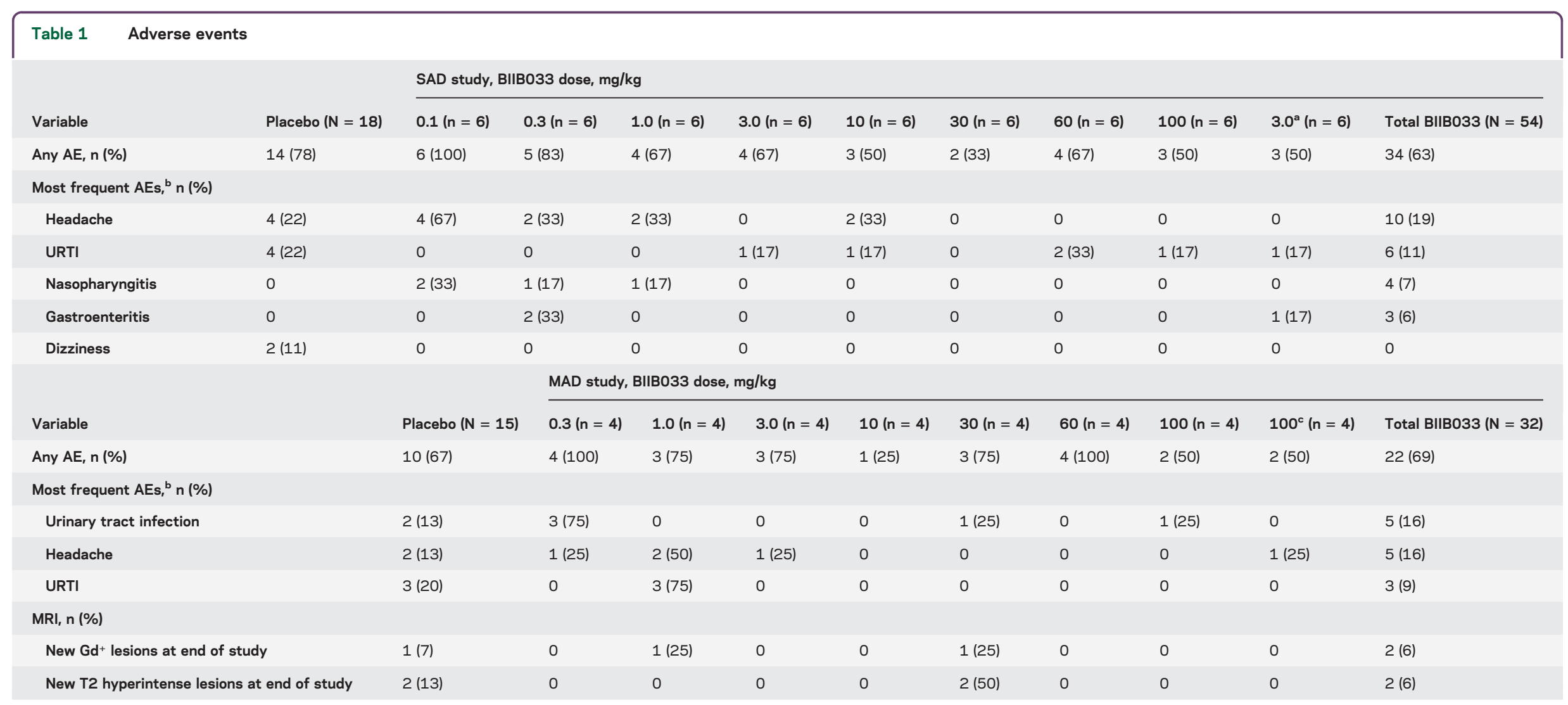

Abbreviations: $\mathrm{AE}=$ adverse event; $\mathrm{Gd}^{+}=$gadolinium enhancing; $\mathrm{MAD}=$ multiple ascending dose; $\mathrm{SAD}=$ single ascending dose; URTI = upper respiratory tract infection.

a Subcutaneous dose.

${ }^{b}$ Occurring in $\geq 2$ participants in any dose group within each study.

${ }^{\mathrm{c}}$ Single dose, shorter infusion time (80 minutes). 
participant in the placebo group withdrew consent (relocated). Overall, SAD participants were about 10 years younger (mean \pm SD, $36.7 \pm 9.6$ years) than MAD participants (mean \pm SD, $47.7 \pm$ 8.8 years). A notably larger percentage of participants were female in the MAD vs SAD studies $(77 \%$ vs $10 \%$ ) due to exclusion of females of childbearing potential from the SAD study. Other baseline demographic and clinical characteristics for SAD and MAD participants are presented in table e- 1 .

Clinical safety. About two-thirds of participants experienced $\geq 1$ AE during the course of the SAD and MAD studies (table 1). There were no serious AEs or deaths during either study. The most commonly reported AEs in both studies were headache, upper respiratory tract infection, nasopharyngitis, gastroenteritis, and urinary tract infection. In the MAD study, 1 participant in the single-dose $100-\mathrm{mg} / \mathrm{kg}$ group with shorter infusion time discontinued treatment due to an allergic reaction. This reaction fully resolved within 1 hour; the participant was treated with antihistamines and completed the study.

For both studies, there were no clinically significant changes in physical examination findings, vital signs, or ECGs. Results from laboratory tests showed that, although there were some sporadic shifts in hematology, blood chemistry (table e-2), and urinalysis results, none were considered to be an AE or clinically significant, and there were no differences in clinical and laboratory safety results for BIIB033- vs placebo-treated participants.

In the SAD study, occasional shifts to abnormal were noted for neurologic examinations, VEPs, SSEPs,
EEG, brain MRI, and retinal examinations (table e-3), although none were considered clinically significant and none were considered an AE. Shifts to abnormal for neurologic examinations were as follows: BIIB033-treated participants, motor ( $\mathrm{n}=2,4 \%$ ), coordination ( $\mathrm{n}=1,2 \%)$, sensory $(\mathrm{n}=1,2 \%)$; placebo-treated participants, sensory $(n=1,6 \%)$.

Immunogenicity. In the SAD study, 3 participants tested positive for anti-BIIB033 antibodies: 1 in the BIIB033 3.0-mg/kg IV group (week 4 only), 1 in the BIIB033 100-mg/kg IV group (day 0 only), and 1 in the placebo group (week 4 and end of study). In the MAD study, 1 placebo-treated participant had positive results for anti-BIIB033 antibodies at days 0 and 14 .

Serum pharmacokinetics. After IV infusion, serum BIIB033 concentration-time profiles in the $\mathrm{PK}$ population of both the SAD study $(\mathrm{n}=53)$ and MAD study ( $\mathrm{n}=31$ ) showed a multi-exponential decrease (figure 2, A and B). The PK values were similar between healthy adults (table 2) and participants with MS (tables 3 and e-4). In both studies, serum BIIB033 exposure (AUC, $\mathrm{C}_{\max }$ ) increased in an approximately dose-proportional manner and mean $t_{1 / 2}$ values spanned from 15 to 24 days (tables 2 and 3). The mean estimated values for $\mathrm{V}_{\text {ss }}$ and mean values for clearance were both low. In the MAD study, serum BIIB033 PK was not detectably affected by concomitant treatment with interferon- $\beta$ $(\mathrm{n}=12)$ or glatiramer acetate $(\mathrm{n}=14$; table e-5). The $\mathrm{C}_{\max }$ and $\mathrm{T}_{\max }$ values for $100 \mathrm{mg} / \mathrm{kg}$ at the faster IV infusion rate (80 minutes) were similar to those observed for the 2.75-hour infusion, indicating that the PK was not affected by the duration of infusion.

Figure 2 Mean serum concentrations of ВІІВ033 vs time
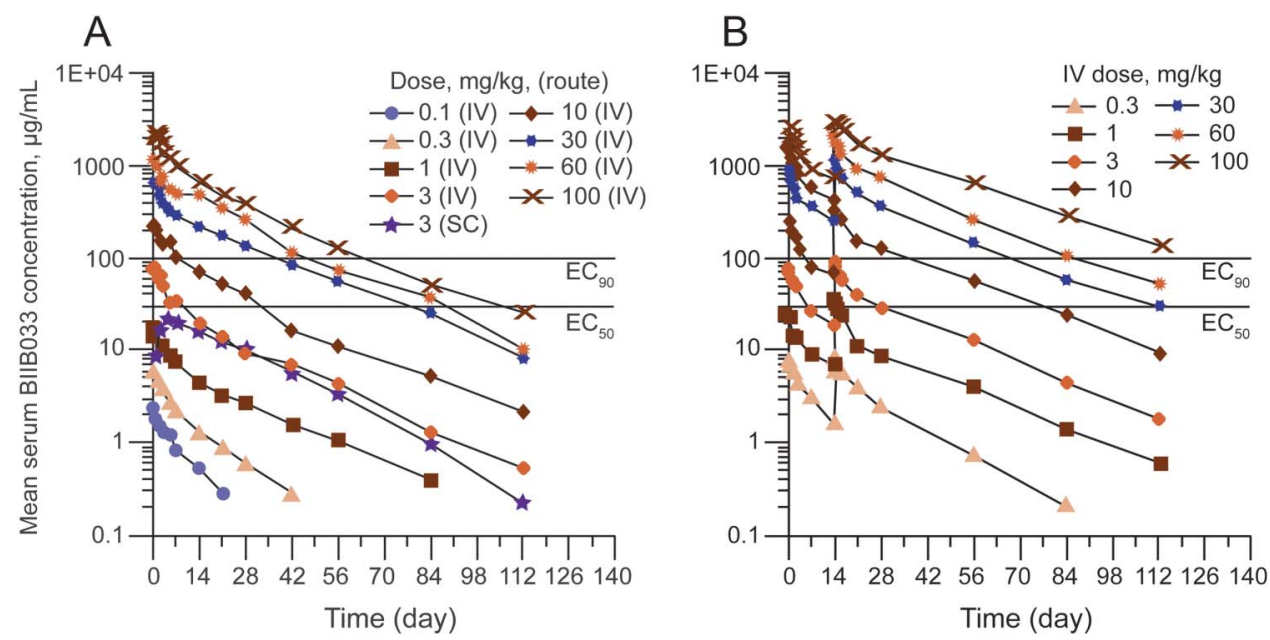

(A) Single ascending dose study and (B) multiple ascending dose study. $\mathrm{EC}_{50}$ and $\mathrm{EC}_{90}$ values determined in rat lysolecithininduced demyelination spinal cord model; values adjusted for $0.1 \%$ brain penetration. Abbreviations: $\mathrm{EC}_{50}$ and $\mathrm{EC}_{90}=50 \%$ and $90 \%$ maximal effective concentrations; SC = subcutaneous. 


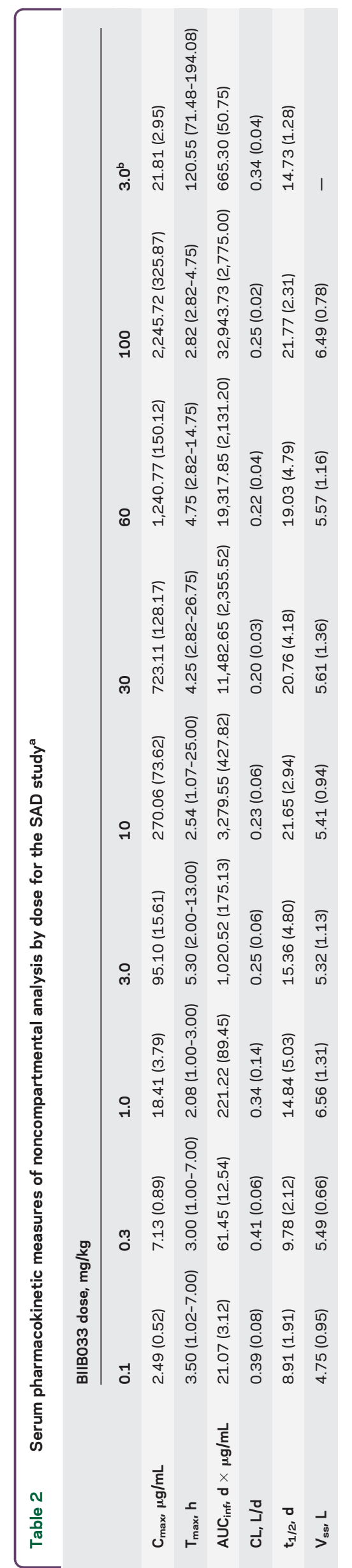

After SC administration, absorption of BIIB033 was slow, with a median $T_{\max }$ of 121 hours ( $\sim 5$ days). However, the mean terminal $t_{1 / 2}$ was about 15 days, which is comparable to that observed after IV dosing. The absolute bioavailability of the $3.0-\mathrm{mg} / \mathrm{kg}$ SC dose was estimated to be $65 \%$. In the only participant who was found to have anti-drug antibodies during treatment with BIIB033 (SAD study, week 4), no effects on serum $\mathrm{PK}$ were evident.

CSF pharmacokinetics. The CSF-to-serum BIIB033 concentration ratios obtained at 2 weeks postdose were highly variable, with interparticipant variability ranging between $43 \%$ and $76 \%$ in healthy volunteers and between $24 \%$ and $54 \%$ in participants with MS (table e-6). In healthy volunteers, the mean CSF/ serum BIIB033 concentration ratios ranged between $0.032 \%$ and $0.079 \%$, with no evidence of dose dependency. Similarly, the mean CSF/serum BIIB033 concentration ratios in participants with MS ranged between $0.030 \%$ and $0.13 \%$, with the exception of a mean ratio of $0.22 \%$ at the $10-\mathrm{mg} / \mathrm{kg}$ dose level, which was not consistent with the trend from other dose levels and was primarily due to the high ratios in 3 participants $(>0.2 \%$ and $<0.3 \%)$. The reason for the higher CSF/serum ratios in these participants is not known. Disease status (i.e., RRMS or SPMS) did not account for this observation because these 3 participants had RRMS (like most other participants in the study). Excluding the high CSF/serum ratios in the 3 participants in the $10-\mathrm{mg} / \mathrm{kg}$ dose group, CSF/serum BIIB033 concentration ratios appeared to increase in a dose-dependent manner, with the mean CSF/serum ratios reaching a plateau at approximately $0.1 \%$.

MRI findings. In the SAD study $(\mathrm{N}=72)$, there were no structural abnormalities, hemorrhage, or infarction among participants, although incidental findings of mucosal thickening in the maxillary sinuses $(\mathrm{n}=2)$ and small venous angioma $(\mathrm{n}=1)$ were noted in 3 BIIB033-treated participants (table e-2). In the MAD study $(\mathrm{N}=47)$, MRI showed no new unexpected findings or increase in $\mathrm{T} 2$ lesions (included all participants) or $\mathrm{Gd}^{+}$lesions (participants with $\mathrm{Gd}^{+}$lesions at baseline: BIIB033, $\mathrm{n}=5$; placebo, $\mathrm{n}=0$ ) in the drug vs placebo group. Overall, slightly smaller percentages of participants in the BIIB033 treatment groups developed new T2 hyperintense lesions or $\mathrm{Gd}^{+}$lesions at the end of the study compared with the placebo groups (table 1). No change in NAWM MTR was observed in either study vs baseline (figure e-1 and data not shown). Results of an exploratory efficacy analysis of change from baseline to week 16 of preexisting T2 and T1 brain lesions on MTR and fractional anisotropy in the MAD study by dose group are shown in figure e- 2 . Some increase in MTR and fractional anisotropy was 


\begin{tabular}{|c|c|c|c|c|c|c|c|c|c|c|c|}
\hline \multirow[t]{4}{*}{ Table 3} & n pharmacokine & tic measures by & $y$ dose for the $M$ & IAD study ${ }^{a}$ & & & & & & & \\
\hline & \multicolumn{11}{|c|}{ ВІІвозЗ dose, $\mathrm{mg} / \mathrm{kg}$} \\
\hline & \multicolumn{2}{|l|}{0.3} & \multicolumn{2}{|l|}{1.0} & \multicolumn{3}{|l|}{3.0} & \multicolumn{4}{|l|}{10} \\
\hline & Dose 1 & Dose 2 & Dose 1 & Dose 2 & Dose 1 & \multicolumn{2}{|c|}{ Dose 2} & \multicolumn{2}{|l|}{ Dose 1} & \multicolumn{2}{|l|}{ Dose 2} \\
\hline$C_{\max , \mu g / m L}$ & 7.6 (1.3) & $8.8(1.9)$ & $26.7(0.3)$ & $35.3(6.3)$ & $77.3(10.3)$ & \multicolumn{2}{|c|}{77.9 (19.2) } & \multicolumn{2}{|c|}{$262.3(60.5)$} & \multicolumn{2}{|c|}{$356.2(51.0)$} \\
\hline$T_{\max }, h$ & $2.0(1.0,6.9)$ & $4.8(1.1,6.9)$ & $2.0(1.1,3.0)$ & $2.0(1.9,3.0)$ & $4.0(1.1,7.0)$ & \multicolumn{2}{|c|}{$1.9(1.9,2.0)$} & \multicolumn{2}{|c|}{$2.1(1.0,25.0)$} & \multicolumn{2}{|c|}{$13.6(2.0,47.7)$} \\
\hline \multirow[t]{3}{*}{$A U C_{\text {taur }} \mu \mathrm{g} \cdot \mathrm{d} / \mathrm{mL}$} & $46.3(5.8)$ & $57.0(6.5)$ & $138.0(35.3)$ & $200.8(59.6)$ & $449.2(62.8)$ & 590.2 & (107.1) & $1,401.4$ & (86.0) & $2,438.9$ & (161.6) \\
\hline & \multicolumn{2}{|l|}{30} & \multicolumn{2}{|l|}{60} & \multicolumn{4}{|l|}{100} & \multicolumn{3}{|l|}{$100^{b}$} \\
\hline & Dose 1 & Dose 2 & Dose 1 & Dose 2 & \multicolumn{2}{|l|}{ Dose 1} & \multicolumn{2}{|l|}{ Dose 2} & \multicolumn{2}{|l|}{ Dose 1} & Dose 2 \\
\hline $\mathrm{C}_{\max , \mu \mathrm{g} / \mathrm{mL}}$ & 868.5 (138.3) & $1,110.9$ (101.7) & 1,680.3 (264.6) & 2,130.2 (416.6) & \multicolumn{2}{|c|}{ 2,673.4 (719.3) } & \multicolumn{2}{|c|}{$3,119.9(541.4)$} & \multicolumn{2}{|c|}{ 2,447.5 (209.8) } & NA \\
\hline$T_{\max }, h$ & $3.3(2.8,4.8)$ & $4.1(3.6,4.7)$ & $2.8(2.8,3.7)$ & $3.7(2.8,8.7)$ & \multicolumn{2}{|l|}{$2.8(2.8,4.8)$} & \multicolumn{2}{|c|}{$8.7(2.8,26.2)$} & \multicolumn{2}{|c|}{$3.2(2.3,7.2)$} & NA \\
\hline $\mathrm{AUC}_{\mathrm{tau}}, \mu \mathrm{g} \cdot \mathrm{d} / \mathrm{mL}$ & 5,383.9 (395.4) & $7,375.5$ (900.6) & $9,233.9(504.4)$ & $14,109.8(1,772.7)$ & \multicolumn{2}{|c|}{ 7) $15,766.0(1,988.4)$} & $25,030.5$ & $(1,007.8)$ & ND & & NA \\
\hline
\end{tabular}

Abbreviations: $\mathrm{AUC}_{\mathrm{tau}}=$ area under the time-concentration curve over a treatment period; $\mathrm{C}_{\max }=$ maximum concentration; $\mathrm{MAD}=$ multiple ascending dose; $N A=$ not applicable; $N D=$ not determined; $T_{\max }=$ time of occurrence of $C_{\max } V_{s s}=$ volume of distribution at steady state.

${ }^{a}$ Data are geometric means and SDs except for $\mathrm{T}_{\max }$ (median, range).

${ }^{b}$ Single dose, shorter infusion time (80 minutes; $\left.n=3\right)$.

apparent in preexisting T2 lesions but not preexisting T1 hypointense lesions for the highest dose groups. In contrast, no significant change in whole brain volume was observed following administration of BIIB033 or placebo at weeks 8 or 16 in the MAD study, and transient changes (week 8 only) in ventricular volume were observed in only the $3.0-\mathrm{mg} / \mathrm{kg}$ and $30-\mathrm{mg} / \mathrm{kg}$ BIIB033 treatment groups (table e-7).

DISCUSSION In these studies evaluating the emerging safety and tolerability of BIIB033 in healthy volunteers and participants with MS, 1 and 2 doses up to $100 \mathrm{mg} / \mathrm{kg}$ were well tolerated. There were no serious AEs in either of the 2 studies. In both studies, the incidence of AEs was similar between the BIIB033- and placebo-treated groups. Most AEs were mild to moderate in severity and not related to study treatment. Development of anti-drug antibodies following administration of BIIB033 was observed in only 1 participant transiently, and it did not have any detectable effect on PK levels or AEs. Among healthy volunteers in the SAD study, no clinically significant findings were observed in the neurologic examinations, brain MRI with MTR, VEPs, SSEPs, EEG, and retinal examination with optical coherence tomography and photography. Together, these results indicate that administration of BIIB033 up to the highest dose of $100 \mathrm{mg} / \mathrm{kg}$ did not have a negative effect on the general health or on the CNS or peripheral nervous system function, including neurons, axons, and their myelin, in either healthy volunteers or participants with RRMS or SPMS.

The BIIB033 serum PK profiles among healthy volunteers and participants with MS were similar and showed linear PK with exposure increasing dose proportionally over the studied dose range of $0.1 \mathrm{mg} / \mathrm{kg}$ to $100 \mathrm{mg} / \mathrm{kg}$. The small volume of distribution indicates that significant target density does not appear to exist within the BIIB033 distribution volume. The low systemic clearance indicates that BIIB033 is not subject to significant target-mediated clearance. These properties are consistent with those reported for other IgG antibodies. ${ }^{12}$ The BIIB033 CSF/serum ratio was also similar to the reported values of approximately $0.1 \%-1 \%$ for other IgG mAb drugs. ${ }^{13,14}$

In rats, CNS penetration for BIIB033 was reported to be low, with brain and CSF exposure approximately $0.16 \%$ and $0.075 \%$ of that in serum, respectively. ${ }^{8}$ Although it is not possible to directly measure levels of BIIB033 in the human brain or spinal cord, based on the similar CSF/serum BIIB033 ratios found in humans from the phase I studies and rats, ${ }^{8}$ it is likely that the brain and spinal cord to plasma ratios of BIIB033 in humans are approximately $0.1 \%$. In the rat lysolecithininduced demyelination spinal cord model, a relationship between anti-LINGO-1 mAb dose $(0.1-100 \mathrm{mg} / \mathrm{kg})$ and response at the target tissue (extent of spinal cord remyelination detectable by histology) was observed. ${ }^{8}$ The CSF concentrations of anti-LINGO-1 mAb associated with $50 \%\left(\mathrm{EC}_{50}\right)$ and $90 \%\left(\mathrm{EC}_{90}\right)$ of maximum remyelinating spinal cord response were approximately $30 \mathrm{ng} / \mathrm{mL}$ and $100 \mathrm{ng} / \mathrm{mL}$, respectively. ${ }^{8}$ These CSF $\mathrm{EC}_{50}$ and $\mathrm{EC}_{90}$ values would correspond to serum $\mathrm{EC}_{50}$ and $\mathrm{EC}_{90}$ values of $30 \mu \mathrm{g} / \mathrm{mL}$ and $100 \mu \mathrm{g} / \mathrm{mL}$, respectively, assuming $0.1 \%$ penetration into the CSF. As illustrated in figure $2, \mathrm{IV}$ doses $>3 \mathrm{mg} / \mathrm{kg}$ and $>10 \mathrm{mg} / \mathrm{kg}$ in participants with MS resulted in mean BIIB033 serum concentrations higher than serum $\mathrm{EC}_{50}$ and serum $\mathrm{EC}_{90}$, suggesting that these doses would be expected to result in pharmacologic activity. 
The pilot exploratory efficacy analysis of BIIB033 effects on preexisting brain MRI lesions by MTR and DTI did not reveal any clear treatment effects on preexisting T2 or T1 lesions (figure e-2). However, the sample size was too small and the duration of treatment too short to allow any firm conclusions to be drawn. Larger and longer studies are necessary to investigate whether MTR and DTI are sensitive enough to detect treatment effects of candidate treatments for CNS repair such as BIIB033.

The findings from these 2 phase I studies of BIIB033 showed that the doses up to $100 \mathrm{mg} / \mathrm{kg}$ were well tolerated and had low immunogenicity. Moreover, the highest doses are expected to result in pharmacologic activity. Thus, the emerging safety, tolerability, and PK profiles of BIIB033 in both healthy volunteers and participants with MS support advancing its clinical development into proof-of-concept phase II studies. A placebo-controlled phase II study in 396 participants with MS commenced in August 2013.

\section{AUTHOR CONTRIBUTIONS}

Drs. Rana, Zhao, and Cadavid participated in the conception/design of the study, analysis/interpretation of the data, and revision of the manuscript, and they approved the final version. Drs. Tran, Barkhof, Melamed, Gevorkyan, Wattjes, Ray, and Xu participated in analysis/ interpretation of the data and revision of the manuscript, and they approved the final version. R. de Jong and K. Brosofsky participated in analysis/interpretation of the data and revision of the manuscript, and they approved the final version. Dr. Parr wrote the first draft of the manuscript with direction from coauthors and approved the final version. Biogen Idec provided funding for writing and editorial support in the development of this paper, and they reviewed and provided feedback on the paper to the authors. The authors had full editorial control of the paper and provided their final approval of all content.

\section{ACKNOWLEDGMENT}

This study was funded by Biogen Idec. Chris Thomas of Excel Scientific Solutions copyedited and styled the manuscript per journal requirements, and this editorial support was funded by Biogen Idec. The authors are grateful to Sha Mi, Gilmore O'Neill, Alfred Sandrock, Carmen Bozic, Nancy Richert, Ramesh Palaparthy, and Mark Rogge of Biogen Idec and Ronald Murray of IMMUNOe for their contributions to the development of BIIB033.

\section{STUDY FUNDING}

Supported by Biogen Idec. Writing and editorial support was funded by Biogen Idec.

\section{DISCLOSURE}

J.Q. Tran holds a patent for "Methods for improving pharmacokinetics," Roche, Patent WO 2010122087 A1; "Compositions comprising HIV protease inhibitor and cytochrome P450 enzyme activity inhibitor," Pfizer, Patent WO 2005082364 A1; is a Biogen Idec Director, Clinical Pharmacology; and has Biogen Idec stock and stock options. J. Rana is a full-time employee of Biogen Idec. F. Barkhof is a scientific consultant to BayerSchering, Sanofi-Aventis, Synthon, Novartis, Biogen Idec, Merck-Serono, GE Medical Systems, Roche, Janssen, TEVA, and Genzyme; is an editorial board member for Brain, European Radiology, Multiple Sclerosis Journal, Neuroradiology, Radiology, and Neurology; has been a speaker for Serono Symposia, Novartis symposium, BioClinica symposium, Bayer-Schering symposium, and Medscape CME; and has received research support from Neugrid4you (FP7 European Committee) and Dutch Foundation for MS Researchcentre grant 2010-2014. I. Melamed reports no disclosures. H. Gevorkyan is employed by the Contracted Research Organization's Medical Group, California Clinical Trials Medical Group, who was compensated for running the study. M.P. Wattjes is on the advisory board for Biogen Idec; has received travel funding/speaker honoraria from Biogen Idec; and is on the editorial board for European Radiology. R. de Jong reports no disclosures. $\mathrm{K}$. Brosofsky is an employee of ALG Partners, Inc, retained to provide study management and oversight; has been a consultant to Biogen Idec; and received compensation from ALG Partners, Inc. S. Ray has been employed by Biogen Idec; has received research support from Biogen Idec; and holds stock with Biogen Idec. L. Xu is employed at Biogen Idec. J. Zhao is a former employee of Biogen Idec. E. Parr is an employee of Excel Scientific Solutions, who was funded by Biogen Idec to provide editorial and writing support for this manuscript. D. Cadavid is an employee of Biogen Idec; is an inventor on a pending patent application related to the use of drugs that block LINGO-1 to treat demyelination in multiple sclerosis; and holds stock with Biogen Idec. Go to Neurology.org/nn for full disclosures.

Received February 20, 2014. Accepted in final form June 19, 2014.

\section{REFERENCES}

1. Llorens F, Gil V, del Río JA. Emerging functions of myelinassociated proteins during development, neuronal plasticity, and neurodegeneration. Faseb J 2011;25:463-475.

2. Mi S, Lee X, Shao Z, et al. LINGO-1 is a component of the Nogo-66 receptor/p75 signaling complex. Nat Neurosci 2004;7:221-228.

3. Rudick RA, Mi S, Sandrock AW Jr. LINGO-1 antagonists as therapy for multiple sclerosis: in vitro and in vivo evidence. Expert Opin Biol Ther 2008;8:1561-1570.

4. Mi S, Pepinsky RB, Cadavid D. Blocking LINGO-1 as a therapy to promote CNS repair: from concept to the clinic. CNS Drugs 2013;27:493-503.

5. Mi S, Miller RH, Lee X, et al. LINGO-1 negatively regulates myelination by oligodendrocytes. Nat Neurosci 2005;8:745-751.

6. Lee X, Yang Z, Shao Z, et al. NGF regulates the expression of axonal LINGO-1 to inhibit oligodendrocyte differentiation and myelination. J Neurosci 2007;27:220-225.

7. Mi S, Hu B, Hahm K, et al. LINGO-1 antagonist promotes spinal cord remyelination and axonal integrity in MOG-induced experimental autoimmune encephalomyelitis. Nat Med 2007;13:1228-1233.

8. Pepinsky RB, Shao Z, Ji B, et al. Exposure levels of antiLINGO-1 Li81 antibody in the central nervous system and dose-efficacy relationships in rat spinal cord remyelination models after systemic administration. J Pharmacol Exp Ther 2011;339:519-529.

9. Price SJ, Tozer DJ, Gillard JH. Methodology of diffusionweighted, diffusion tensor and magnetisation transfer imaging. Br J Radiol 2011;84(Spec No 2):S121-S126.

10. Polman $\mathrm{CH}$, Reingold SC, Edan G, et al. Diagnostic criteria for multiple sclerosis: 2005 revisions to the "McDonald Criteria”. Ann Neurol 2005;58:840-846.

11. Kurtzke JF. Rating neurologic impairment in multiple sclerosis: an expanded disability status scale (EDSS). Neurology 1983;33:1444-1452.

12. Dirks NL, Meibohm B. Population pharmacokinetics of therapeutic monoclonal antibodies. Clin Pharmacokinet 2010;49:633-659.

13. Deng R, Jin F, Prabhu S, Iyer S. Monoclonal antibodies: what are the pharmacokinetic and pharmacodynamic considerations for drug development? Expert Opin Drug Metab Toxicol 2012;8:141-160.

14. Petereit HF, Rubbert-Roth A. Rituximab levels in cerebrospinal fluid of patients with neurological autoimmune disorders. Mult Scler 2009;15:189-192. 


\title{
Neurology ${ }^{\oplus}$ \\ Neuroimmunology \& Neuroinflammation
}

\author{
Randomized phase I trials of the safety/tolerability of anti-LINGO-1 monoclonal \\ antibody BIIB033 \\ Jonathan Q. Tran, Jitesh Rana, Frederik Barkhof, et al. \\ Neurol Neuroimmunol Neuroinflamm 2014;1; \\ DOI 10.1212/NXI.0000000000000018
}

This information is current as of August 27, 2014

Neurol Neuroimmunol Neuroinflamm is an official journal of the American Academy of Neurology.

Published since April 2014, it is an open-access, online-only, continuous publication journal. Copyright $(\mathrm{C}$ 2014 American Academy of Neurology. All rights reserved. Online ISSN: 2332-7812.

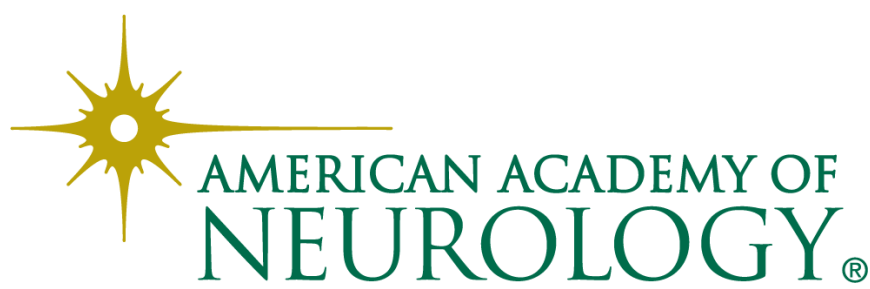




\section{Updated Information \& Services}

\section{Supplementary Material}

\section{References}

Citations

Subspecialty Collections

\section{Permissions \& Licensing}

Reprints including high resolution figures, can be found at: http://nn.neurology.org/content/1/2/e18.full.html

Supplementary material can be found at: http://nn.neurology.org/content/suppl/2014/08/27/1.2.e18.DC1 http://nn.neurology.org/content/suppl/2014/08/27/1.2.e18.DC2

This article cites 14 articles, 3 of which you can access for free at: http://nn.neurology.org/content/1/2/e18.full.html\#\#ref-list-1

This article has been cited by 2 HighWire-hosted articles: http://nn.neurology.org/content/1/2/e18.full.html\#\#otherarticles

This article, along with others on similar topics, appears in the following collection(s):

Clinical trials Randomized controlled (CONSORT agreement)

http://nn.neurology.org//cgi/collection/clinical_trials_randomized_cont rolled_consort_agreement

Multiple sclerosis

http://nn.neurology.org//cgi/collection/multiple_sclerosis

Information about reproducing this article in parts (figures,tables) or in its entirety can be found online at:

http://nn.neurology.org/misc/about.xhtml\#permissions

Information about ordering reprints can be found online: http://nn.neurology.org/misc/addir.xhtml\#reprintsus

Neurol Neuroimmunol Neuroinflamm is an official journal of the American Academy of Neurology.

Published since April 2014, it is an open-access, online-only, continuous publication journal. Copyright $\odot$ 2014 American Academy of Neurology. All rights reserved. Online ISSN: 2332-7812.

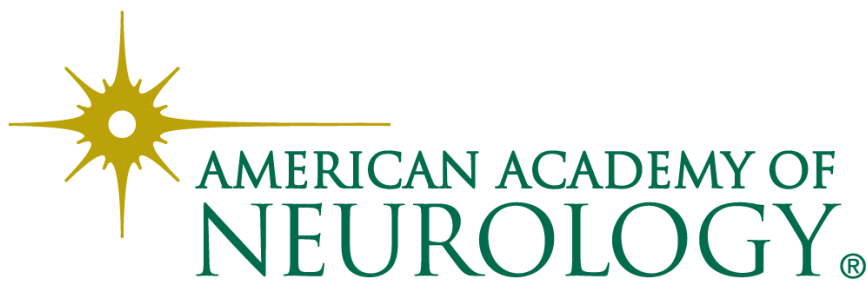

